\section{Commentary: The endless debate of extent of surgical repair in acute aortic dissection: Skill, judgment, and luck}

\author{
Ali Hage, MD, Matthew Valdis, MD, FRCSC, and \\ Michael W. A. Chu, MD, FRCSC
}

Despite improved surgical techniques, advances in brain protection, and accrued individual and aortic team experience, surgery for acute type A aortic dissection (ATAAD) is still associated with significant morbidity and mortality. The debate continues on whether the anticipated late benefits from more aggressive aortic root and extended arch repair outweigh the increased early perioperative risk of more extensive primary aortic reconstruction, particularly at inopportune times of hemodynamic instability, malperfusion, the emergent setting, or with less-experienced surgical teams.

In their recent manuscript, Uchida and colleagues ${ }^{1}$ presented their experience in 253 patients with ATAAD who underwent ascending aorta/hemiarch replacement versus total arch replacement with a conventional elephant trunk. The authors reported excellent early outcomes with low mortality and stroke risks in both groups. At 4 years' follow-up, patients who underwent ascending aortic/hemiarch replacement had greater rates of distal aortic events, with nonthrombosis of the arch false lumen being the most important predictor of long-term aortic complications. There were significant baseline differences between the 2 groups and likely important selection biases, which must be accounted for when interpreting the results.

Regardless, this paper adds to the growing body of literature supporting more aggressive arch reconstruction in primary ATAAD operations. The surgical dogma of resecting the primary intimal entry tear and getting out of the

From Western University, London, Ontario, Canada.

Disclosures: Authors have nothing to disclose with regard to commercial support.

Received for publication March 2, 2020; accepted for publication March 3, 2020; available ahead of print March 18, 2020.

Address for reprints: Michael W. A. Chu, MD, FRCSC, B6-106 University Hospital, London Health Sciences Centre, 339 Windermere Rd, London, Ontario, Canada (E-mail: Michael.Chu@1hsc.on.ca).

J Thorac Cardiovasc Surg 2021;162:1032-3

$0022-5223 / \$ 36.00$

Copyright (c) 2020 by The American Association for Thoracic Surgery

https://doi.org/10.1016/j.jtcvs.2020.03.024

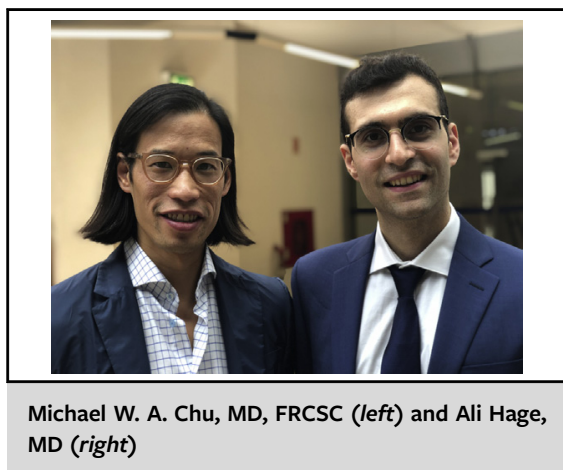

CENTRAL MESSAGE

Performing an extended arch

repair in acute type $A$ aortic

dissection may prevent future

distal aortic events, but only if

patients survive the initial

operation.

operating room with an alive patient still holds true; however, we have evolved beyond these simplistic goals. Most patients after standard hemiarch repair continue to have persistent false lumen flow. As a result, residual dissected aorta remains diseased aorta at risk for aneurysmal growth and complications of persistent false lumen flow. We must tailor the aortic reconstructive plan for each patient, carefully evaluating the early and late benefits of a more extensive repair, especially in the setting of connective tissue disorders and younger patients, while balancing the optimal perioperative risks. Recent evidence supports the use of contemporary cerebral-protection strategies to improve survival and neurologic outcomes in more extensive arch reconstruction. $^{2}$

To extend the argument even further, several centers have advocated for the liberal use of frozen elephant trunk reconstruction to aggressively promote distal aortic remodeling and facilitating potential downstream endovascular interventions. ${ }^{3}$ Many early-adopter groups have been able to achieve good early clinical and radiographic outcomes, albeit at the cost of increased paraplegia.

In summary, performing "the best surgery" depends on both the patient's presentation and the surgical team's expertise. With the proper skill set and the right judgment, experienced surgeons should perform a repair that optimizes both the short- and long-term outcomes. 


\section{References}

1. Uchida K, Minami T, Cho T, Yasuda S, Kasama K, Suzuki S, et al. Results of ascending aortic and arch replacement for type A aortic dissection. J Thorac Cardiovasc Surg. 2021;162:1025-31.

2. Hage A, Stevens LM, Ouzounian M, Chung J, El-Hamamsy I, Chauvette V, et al. Impact of brain protection strategies on mortality and stroke in patients undergo- ing aortic arch repair with hypothermic circulatory arrest: evidence from the Canadian thoracic aortic collaborative. Eur J Cardiothorac Surg. February 8, 2020 [Epub ahead of print].

3. Hanif H, Dubois L, Ouzounian M, Peterson MD, El-Hamamsy I, Dagenais F, et al Aortic arch reconstructive surgery with conventional techniques vs frozen elephant trunk: a systematic review and meta-analysis. Can J Cardiol. 2018;34:262-73.
See Article page 1025 .

\section{Commentary: Strategic surgery to type A dissection: A bird in the hand or 2 in the bush?}

\author{
Christoph A. Nienaber, MD, PhD, and \\ Xun Yuan, MBBS, MMED
}

Congratulations to the authors. Uchida and colleagues ${ }^{1}$ show that in the setting of acute type A aortic dissection mortality for both a limited strategy of replacing the ascending aorta or hemi-arch (AAR), and an extensive strategy of total arch repair (TAR) with classic or frozen elephant trunk, were only $7.1 \%$ and $6.0 \%$, respectively; thus, even better than recently published results from peers quoting $10.4 \%$ and $11.3 \%$, respectively. ${ }^{2}$ Because TAR was associated with less-frequent late distal complications or events after years of follow-up, they concluded to recommend changing from an entry-oriented strategy to prolific use of TAR even instead of AAR to prevent those late distal events and thereby improving quality of life (QoL).

A stark statement, but is it based on solid foundation? First, the study design is retrospective over 12 years, neither randomized nor controlled, and rather a report on the experience with 253 patients managed in a single center of excellence. We are not sure that the ivory tower

\footnotetext{
From the Cardiology and Aortic Centre, Royal Brompton and Harefield Hospital NHS Foundation Trust, London, United Kingdom; and the Department of Cardiology, National Heart and Lung Institute, Faculty of Medicine, Imperial College London, London, United Kingdom.

Disclosure: Authors have nothing to disclose with regard to commercial support

Received for publication Feb 27, 2020; revisions received Feb 27, 2020; accepted for publication Feb 27, 2020; available ahead of print March 19, 2020.

Address for reprints: Christoph A. Nienaber, MD, PhD, Cardiology and Aortic Centre, Royal Brompton and Harefield Hospital NHS Foundation Trust, London SW3 6NP United Kingdom (E-mail: c.nienaber@rbht.nhs.uk).

J Thorac Cardiovasc Surg 2021;162:1033-4 $0022-5223 / \$ 36.00$

Copyright (c) 2020 Published by Elsevier Inc. on behalf of The American Association for Thoracic Surgery

https://doi.org/10.1016/j.jtcvs.2020.02.120
}

Check for updates

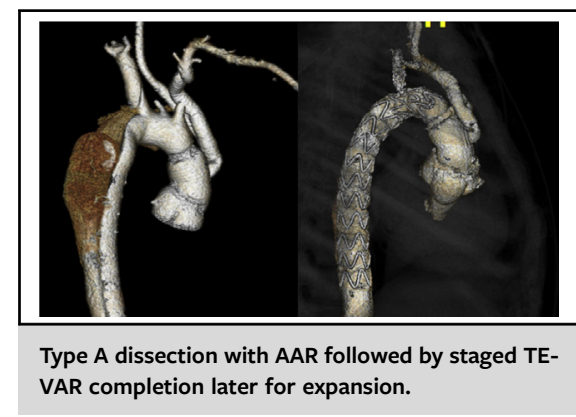

CENTRAL MESSAGE

A postponed secondary elective surgery or endovascular repair could be embraced for strategic risk control in the setting of type A dissection.

experience justify a strategic change of management on the ground. Second, the currently popular standard strategy focusing on entry exclusion, obviously in the spirit of Kazui and colleagues, ${ }^{3}$ has led to some preselection of 2 out of 3 patients for AAR/hemiarch versus 1 out of 3 for the more extensive TAR, both with excellent mortality figures despite different demographics. Without any risk adjustment made, TAR was applied to younger and more stable patients, whereas AAR requires more frequent additional surgery (eg, root replacement, bypasses, and more) in a sicker and older population; this is likely to skew survival rates and render it difficult to justify any expanding use of TAR to less stable patients in their current AAR population for the sake of fewer distal problems in the future. Third, and of note those reported differences regarding late peripheral events and QoL are at best assumptions considering a late rupture rate of only $3.6 \%$ after TAR versus $2.9 \%$ after AAR, and with no mentioning of any measures of QoL. Moreover, late events such as degeneration of the distal aorta 